\title{
Long-term disease-free survivor of metastatic large-cell neuroendocrine carcinoma of the lung treated with amrubicin and irinotecan
}

This article was published in the following Dove Press journal:

Drug Design, Development and Therapy

10 July 2009

Number of times this article has been viewed

\author{
Shinichiro Ryuge' \\ Shi-Xu Jiang ${ }^{2}$ \\ Mayuko Wada' \\ Ken Katono' \\ Maiko Iwasaki' \\ Akira Takakura' \\ Sakiko Otani ${ }^{\prime}$ \\ Yuka Kimura' \\ Tomoya Fukui' \\ Masanori Yokoba' \\ Masaru Kubota' \\ Masato Katagiri' \\ Kazusige Hayakawa ${ }^{3}$ \\ Noriyuki Masuda \\ 'Department of Respiratory \\ Medicine, ${ }^{2}$ Department of Pathology, \\ ${ }^{3}$ Department of Radiology, Kitasato \\ University School of Medicine, \\ Sagamihara, Kanagawa, Japan
}

Correspondence: Noriyuki Masuda Department of Respiratory Medicine, Kitasato University School of Medicine, I-I5-I Kitasato, Sagamihara, Kanagawa 228-0022, Japan

Tel $+8 \mid 427788$ III

Fax +8I 427786412

Email masuda@med.kitasato-u.ac.jp

\begin{abstract}
Large-cell neuroendocrine carcinoma (LCNEC) is a relatively uncommon variant of non-small cell lung cancer. Since the biological characteristics of LCNEC are similar to those of small cell lung cancer, LCNEC is usually treated with chemotherapy regimens used for small cell lung cancer. However, the outcomes are usually dismal. Here, we report a patient with LCNEC (a metastasis to the brain). After whole brain irradiation, he received a combination of amrubicin and irinotecan chemotherapy, and has been relapse-free for two years. This treatment regimen may be beneficial for patients with advanced LCNEC.

Keywords: large-cell neuroendocrine carcinoma, chemotherapy, amrubicin, irinotecan, lung cancer

\section{Introduction}

Large-cell neuroendocrine carcinoma of the lung (LCNEC) was first proposed by Travis and colleagues ${ }^{1}$ in 1991 as a separate fourth category of pulmonary neuroendocrine tumors, in addition to typical carcinoid tumor, atypical carcinoid tumor and small-cell lung cancer. The incidence of LCNEC is very low, and appears to be between $2.1 \%$ and $3.5 \% .{ }^{2}$ The clinical outcome of LCNEC is reported to be poorer than that of stage-comparable conventional non-small-cell lung cancer. ${ }^{3,4}$ LCNEC belongs, together with small-cell lung cancer, to a group of high-grade malignancies, and the prognosis of patients with LCNEC falls between that of patients with atypical carcinoid tumor and those with small-cell lung cancer. ${ }^{1}$ Little information on chemotherapy for advanced LCNEC exists, and a standard treatment strategy for advanced LCNEC is far from being established. ${ }^{5-8}$ Here, we report a patient with stage IV LCNEC who achieved a complete response after undergoing whole brain irradiation followed by a combination of amrubicin and irinotecan chemotherapy.
\end{abstract}

\section{Case report}

In February 2007, a 66-year-old male patient was transferred to the Kitasato University Hospital after an annual check-up chest X-ray revealed a nodule in the right lower field of his lung. The patient denied having fever, weight loss, or hemoptysis. He had smoked 2.5 packs of cigarettes a day for 40 years. His medical and social histories were unremarkable. On physical examination, no significant abnormalities were found. The results of routine laboratory studies, including a complete blood count, platelet, and blood chemistry screening, were normal, including the tumor 
marker levels (carcinoembrionic antigen, neuron-specific enolase, and pro-gastrin-releasing peptide). A computed tomography (CT) of the lung confirmed a nodule in the right lower lobe with no signs of mediastinal lymphadenopathy (Figure 1A). Metastatic multiple tiny pulmonary nodules were not observed.

Soon after his first visit, he started to complain of rapidly developing dysarthria, right hemiparesis, and gait disturbance. A solitary metastasis with a midline shift (2.6 cm in diameter) was identified on a brain CT examination (Figure 2A). Since we could not rule out the diagnosis of small cell lung cancer which has a high propensity for early micrometastases, whole-brain irradiation was first given in March 2007, with a total dose of 50 Gy delivered in 25 fractions; this treatment resulted in a marked symptomatic and a good radiological partial response (Figure 2B).
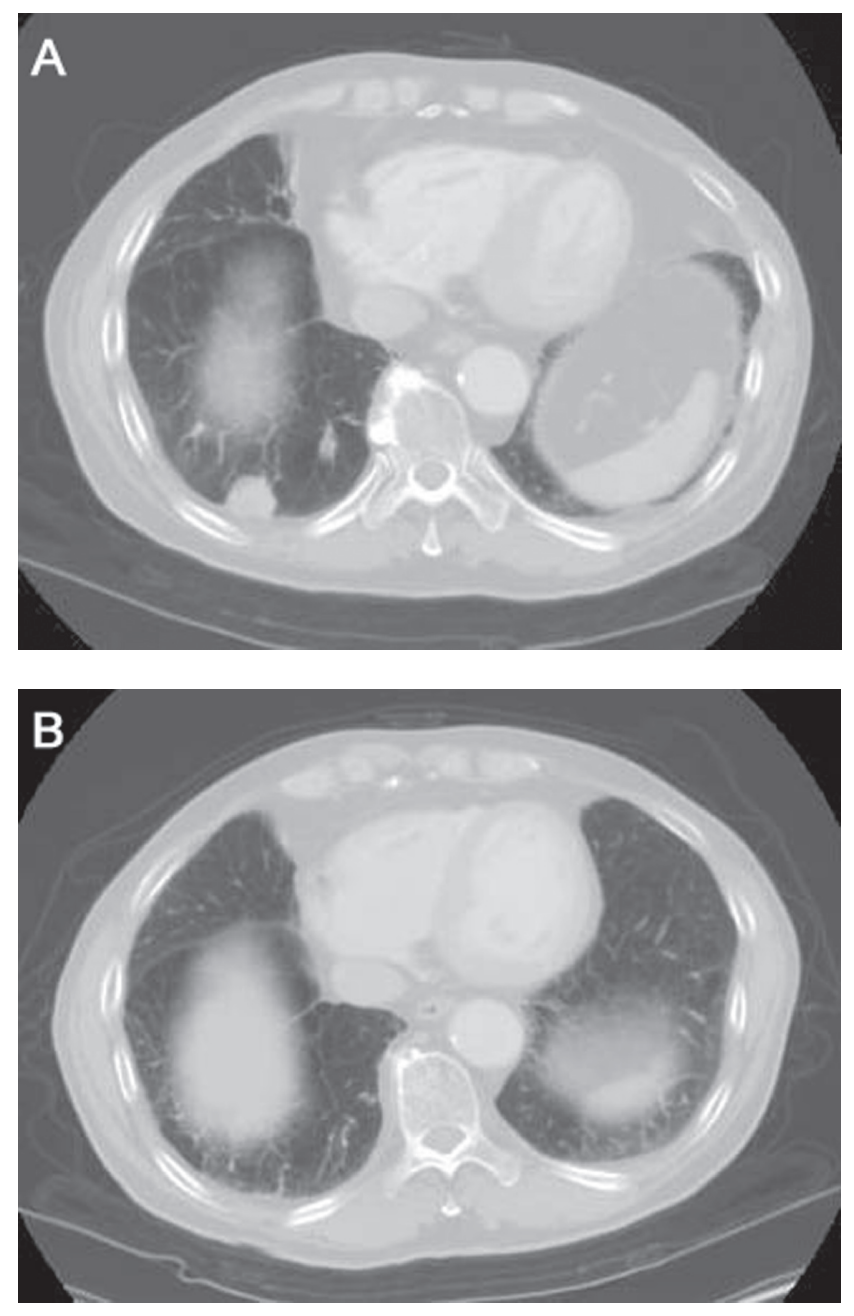

Figure I Computed tomography image of the chest showing a solitary nodule measuring $26 \mathrm{~mm}$ in diameter in the right lower lobe (A:May 2007) and the complete response to four cycles of a combination of amrubicin and irinotecan (B: January 2009).
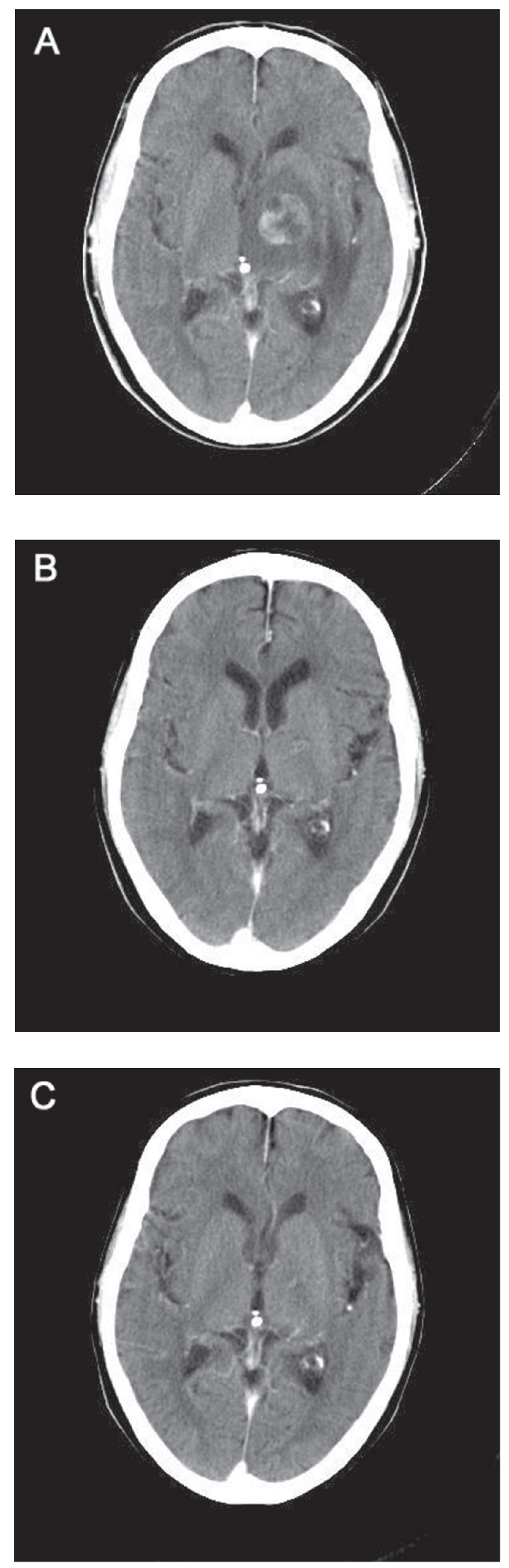

Figure 2 Computed tomography image of the brain showing the brain metastasis before treatment (A: March 2007), the good response to whole brain irradiation (B: May 2007), and the complete resolution of the brain disease (C: January 2009). 
A fiberoptic bronchoscopy was carried out, but a diagnosis could not be confirmed. A CT-guided percutaneous needle biopsy of the tumor was subsequently performed. Histologically, tumor cells were arranged in nests or trabeculae, and infiltrated in the fibrous stroma. Individual tumor cells were polygonal in shape with relatively abundant cytoplasm and vesicular nucleus. Coagulative tumor necrosis was also observed (Figure 3A). Immunohistochemistry showed positive staining for $\mathrm{CD} 56$, protein-gene product 9.5 (PGP 9.5) and neuron-specific enolase (NSE) (Figure 3B). Thus, the tumor was diagnosed as LCNEC. Additional examinations, including bone scanning and an upper abdominal CT, showed no signs of abnormalities. Therefore, the patient was staged as having T1N0M1. He discontinued smoking at the time of his diagnosis.

After whole-brain irradiation, the patient was treated at three-week intervals with $25 \mathrm{mg} / \mathrm{m}^{2}$ of amrubicin (5-min intravenous injection on days 1-3) plus $60 \mathrm{mg} / \mathrm{m}^{2}$ of CPT-11 (90-min intravenous infusion on days 1 and 8) starting in May 2007. The selection of this regimen was based on our previous phase I trial. ${ }^{9}$ Out of 11 patients entered onto the trial, five partial responses were obtained. One good partial response was observed only in a patient with neuroendocrine properties who had huge liver metastases. He received four cycles of this chemotherapy, ending in mid-August 2007, and a chest X-ray showed that the primary lesion had rapidly decreased in size from $2.5 \mathrm{~cm} \times 2.6 \mathrm{~cm}$ to $1.4 \mathrm{~cm} \times 0.7 \mathrm{~cm}$ within two weeks. A further follow-up CT examination showed the complete resolution of both the primary lesion and the brain metastasis, and the patient's quality of life was improved (Figures 1B, 2C). As of
March 1, 2009, he has been progression-free from disease for a total of 24 months.

\section{Discussion}

Because of the difficulty in making an immunohistochemical diagnosis using small specimens, LCNEC is often difficult to diagnose correctly using small specimens obtained by bronchoscopy or fine needle biopsy..$^{10}$ Although LCNEC is categorized as a variant of large-cell carcinoma, ${ }^{11}$ LCNEC exhibits features of a high-grade neuroendocrine tumor, and the biological behavior of LCNEC tumors resembles that of small cell lung carcinomas. LCNEC has a worse prognosis than stage-equivalent NSCLC. ${ }^{2}$ Specimens obtained using fiber-optic bronchoscopy or percutaneous fine needle aspiration should be carefully examined because the accurate differentiation of LCNEC from the more common large cell lung cancer is important for identifying patients with a dismal prognosis. Rossi and colleagues ${ }^{7}$ reported that platinum-doublet chemotherapy regimens that are generally recommended for NSCLC, including cisplatin plus gemcitabine, were relatively ineffective and that the use of standard chemotherapy regimens for SCLC seemed to be the most important survival-related variable. Iyoda and colleagues ${ }^{12}$ described a survival benefit in patients with surgically resected stage I LCNEC who underwent a standard adjuvant chemotherapy regimen typically used for SCLC patients. Kozuki and colleagues ${ }^{6}$ also stated in their study of 12 LCNEC patients that combination therapy of cisplatin plus etoposide was useful for improving outcome. In a retrospective analysis, Yamazaki and colleagues ${ }^{8}$ reported a $50 \%$ response rate to cisplatin-based chemotherapy in
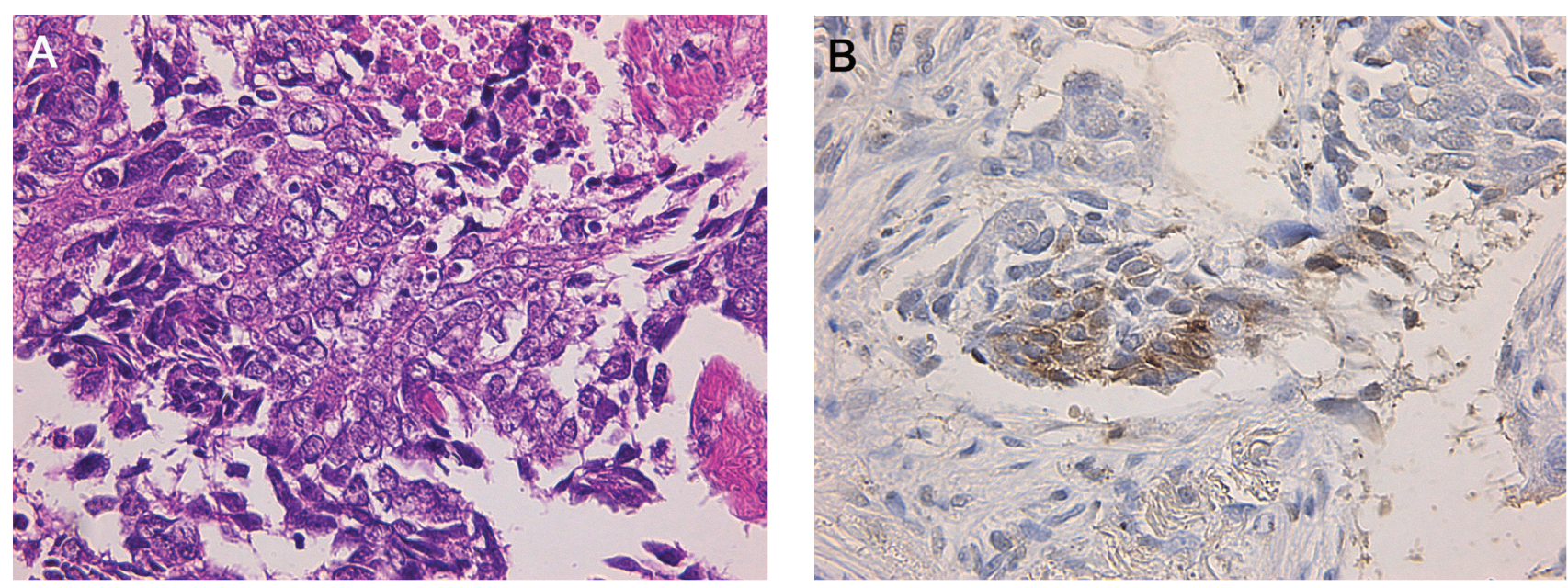

Figure 3 Histologic and immunohistochemical analysis of the tumor specimen obtained during a computed tomography-guided percutaneous tumor biopsy. A: individual tumor cells were polygonal in shape with relatively abundant cytoplasm and vesicular nucleus, and were arranged in nests with area of coagulative necrosis. B:Tumor cells 
20 LCNEC patients. Fujiwara and colleagues ${ }^{5}$ suggested that a regimen comprised of a platinum-doublet combined with irinotecan (CPT-11) or paclitaxel might be active against LCNEC. All these authors recommended that LCNECs should be treated in a manner similar to that used for small cell lung cancer, given their similarity in chemosensitivity and aggressive characteristics, even though LCNECs are classified as non-small cell lung cancer. Amrubicin is a totally synthetic anthracycline anticancer agent that acts as a potent topoisomerase II inhibitor. Amrubicin is converted to an active metabolite, amrubicinol. ${ }^{13}$ The response rates to amrubicin in patients with non-small cell lung cancer and small cell lung cancer were $25 \%$ and $52 \%-79 \%$, respectively. ${ }^{14-16} \mathrm{CPT}-11$ is a water-soluble camptothecin derivative that inhibits topoisomerase I. CPT-11 has shown a significant antitumor activity against various human malignancies including non-small cell lung cancer and small cell lung cancer. ${ }^{17-20}$ DNA topoisomerase I and II are functionally related and are known to act in concert. Since the combined use of topoisomerase I and II inhibitors is theoretically attractive because of the complementary functions of their targets, ${ }^{21}$ we previously conducted a phase I study of amrubicin combined with CPT-11 for the treatment of advanced non-small cell lung cancer. ${ }^{9}$ During this trial, one good PR was obtained in a patient with LCNEC. Similar to this previous experience, the present case also showed a marked response to the nonplatinum doublet of amrubicin and CPT-11, with a progression-free survival period of 24 months. To our knowledge, this is the first report describing the use of a nonplatinum doublet for advanced LCNEC. Since the combination of cisplatin and etoposide has been used extensively for the treatment of this disease, our case report adds to the medical literature on the use of amrubicin and CPT-11 regimens for the treatment of this increasingly recognized malignancy, which has a dismal prognosis and a high and early propensity to metastasize. However, Rossi and colleagues $^{7}$ reported the median diameter of their LCNEC tumors was $40 \mathrm{~mm}$. Our tumor size was $26 \mathrm{~mm}$. The small tumor volume may have good influence on the response to the combination regimen of amrubicin and CPT-11. However, it is difficult to make valid conclusions about the ultimate clinical activity of this combination regimen on the basis of this case report. Therefore, phase II/III trials are needed to allow a precise estimate of the degree of activity of this regimen against advanced $\mathrm{LCNEC}$.

In conclusion, the combination of amrubicin and CPT-11 is a promising and well-tolerated regimen based on its unique mechanisms of action and may be a novel therapeutic approach capable of improving the survival rates of patients with LCNEC, a very rare but aggressive neuroendocrine tumor.

\section{Disclosure}

The authors report no conflicts of interest in this work.

\section{References}

1. Travis WD, Linnoila RI, Tsokos MG, et al. Neuroendocrine tumors of the lung with proposed criteria for large-cell neuroendocrine carcinoma. An ultrastructural, immunohistochemical, and flow cytometric study of 35 cases. Am J Surg Pathol. 1991;15:529-553.

2. Fernandez FG, Battafarano RJ. Large-cell neuroendocrine carcinoma of the lung: an aggressive neuroendocrine lung cancer. Semin Thorac Cardiovasc Surg. 2006;18:206-210.

3. Dresler CM, Ritter JH, Patterson GA, Ross E, Bailey MS, Wick MR. Clinical-pathologic analysis of 40 patients with large cell neuroendocrine carcinoma of the lung. Ann Thorac Surg. 1997;63: $180-185$.

4. Jiang SX, Kameya T, Shoji M, Dobashi Y, Shinada J, Yoshimura H. Large cell neuroendocrine carcinoma of the lung: a histologic and immunohistochemical study of 22 cases. Am J Surg Pathol. 1998;22: 526-537.

5. Fujiwara Y, Sekine I, Tsuta K, et al. Effect of platinum combined with irinotecan or paclitaxel against large cell neuroendocrine carcinoma of the lung. Jpn J Clin Oncol. 2007;37:482-486.

6. Kozuki T, Fujimoto N, Ueoka H, et al. Complexity in the treatment of pulmonary large cell neuroendocrine carcinoma. J Cancer Res Clin Oncol. 2005;131:147-151.

7. Rossi G, Cavazza A, Marchioni A, et al. Role of chemotherapy and the receptor tyrosine kinases KIT, PDGFRalpha, PDGFRbeta, and Met in large-cell neuroendocrine carcinoma of the lung. J Clin Oncol. 2005;23:8774-8785.

8. Yamazaki S, Sekine I, Matsuno Y, et al. Clinical responses of large cell neuroendocrine carcinoma of the lung to cisplatin-based chemotherapy. Lung Cancer. 2005;49:217-223.

9. Yanaihara T, Yokoba M, Onoda S, et al. Phase I and pharmacologic study of irinotecan and amrubicin in advanced non-small cell lung cancer. Cancer Chemother Pharmacol. 2007;59:419-427.

10. Mazieres J, Daste G, Molinier L, et al. Large cell neuroendocrine carcinoma of the lung: pathological study and clinical outcome of 18 resected cases. Lung Cancer. 2002;37:287-292.

11. Travis W, Colby T, Corrin B, Shimosato Y, Brambilla E. Histological typing of lung and pleural tumours. Berlin, Germany: Springer Verlag; 1999.

12. Iyoda A, Hiroshima K, Nakatani Y, Fujisawa T. Pulmonary large cell neuroendocrine carcinoma: its place in the spectrum of pulmonary carcinoma. Ann Thorac Surg. 2007;84:702-707.

13. Yamamoto M, Takakura A, Masuda N. Next-generation anthracycline for the management of small cell lung cancer: focus on amrubicin. Drug Design, Development and Therapy. 2008;2:189-192.

14. Furuse K, Ikegami H, Ariyoshi Y. Two phase II studies of amrubicin (SM-5887), a novel 9-amino-anthracycline, in patients with advanced non-small cell lung cancer (NSCLC): West Japan Lung Cancer Group Trials [abstract]. Ann Oncol. 1988;9(Suppl 4):88, \#422.

15. Onoda S, Masuda N, Seto T, et al. Phase II trial of amrubicin for treatment of refractory or relapsed small-cell lung cancer: Thoracic Oncology Research Group Study 0301. J Clin Oncol. 2006;24: 5448-5453.

16. Yana T, Negoro S, Takada Y, Yokota S, Fukuoka M; West Japan Lung Cancer Group. Phase II study of amrubicin (SM-5887). a 9-aminoanthracycline, in previously untreated patients with extensive stage small-cell lung cancer (ES-SCLC): a West Japan Lung Cancer Group trial. Proc Am Soc Clin Oncol. 1998;17:450a. 
17. Fukuoka M, Niitani H, Suzuki A, et al. A phase II study of CPT-11, a new derivative of camptothecin, for previously untreated non-small-cell lung cancer. J Clin Oncol. 1992;10:16-20.

18. Langer CJ. The global role of irinotecan in the treatment of lung cancer: 2003 update. Oncology (Williston Park). 2003;17:30-40.

19. Masuda N, Fukuoka M, Kusunoki Y, et al. CPT-11: a new derivative of camptothecin for the treatment of refractory or relapsed small-cell lung cancer. J Clin Oncol. 1992;10:1225-1229.
20. Masuda N, Kudoh S, Fukuoka M. Irinotecan (CPT-11): pharmacology and clinical applications. Crit Rev Oncol Hematol. 1996;24:3-26.

21. Vasey PA, Kaye SB. Combined inhibition of topoisomerases I and II - is this a worthwhile/feasible strategy? Br J Cancer. 1997;76: 1395-1397.

\section{Publish your work in this journal}

Drug Design, Development and Therapy is an international, peerreviewed open-access journal that spans the spectrum of drug design and development through to clinical applications. Clinical outcomes, patient safety, and programs for the development and effective, safe, and sustained use of medicines are a feature of the journal, which has also been accepted for indexing on PubMed Central. The manuscript management system is completely online and includes a very quick and fair peer-review system, which is all easy to use. Visit http://www.dovepress.com/testimonials.php to read real quotes from published authors.

Submit your manuscript here: http://www.dovepress.com/drug-design-development-and-therapy-journal 